\title{
The Defects and Improvements of the Internal Control Audit in Chinese Universities with respect to the Probabilistic Hesitant Fuzzy Environment
}

\author{
Jingjuan Zhu $₫,{ }^{1}$ Ling Xu, ${ }^{2}$ Yunzhong Liu, ${ }^{2}$ Dawei $\mathrm{Zhu},{ }^{2}$ and Liangliang Chen ${ }^{2}$ \\ ${ }^{1}$ Audit Office, Southeast University, Nanjing 210096, China \\ ${ }^{2}$ School of Finance, Nanjing Agricultural University, Nanjing 210095, China \\ Correspondence should be addressed to Jingjuan Zhu; 101012354@seu.edu.cn
}

Received 21 April 2021; Revised 16 May 2021; Accepted 27 May 2021; Published 11 June 2021

Academic Editor: Zeshui Xu

Copyright (C) 2021 Jingjuan Zhu et al. This is an open access article distributed under the Creative Commons Attribution License, which permits unrestricted use, distribution, and reproduction in any medium, provided the original work is properly cited.

\begin{abstract}
This paper analyzes the survey data and qualitative evaluation information of the internal control audit of some universities directly under the Ministry of Education of China (MEC) by using the principal component analysis. The qualitative evaluation information is given by experts and presented by the probabilistic hesitant fuzzy elements. The analysis results show that the internal control audit system and process are not perfect, the professional knowledge and skills of internal auditors in universities are not very adaptable to internal control audit, and the effectiveness of internal control audit management conducted by external firms is not good. These are the three most serious defects of the current internal control audit in universities. The most critical factors influencing the quality of internal control audit in universities are, in order, the difficulty of rational use of the results of internal control audit by universities, the poor support of the leadership for internal control audit, and the insufficient professional knowledge and skills of internal auditors to conduct internal control audit. Thus, this paper proposes that the optimization suggestions for the internal control audit of universities are to establish and improve their internal control audit system and process to continually promote the application of internal control audit results, to increase the degree of attention of the leadership, and to strengthen the construction of the internal audit teams.
\end{abstract}

\section{Introduction}

At the end of 2012, the Ministry of Finance issued the "Regulation for Internal Control of Administrative Institutions (for Trial Implementation)" (Finance and Accounting (2012) No. 21, China), requiring that the regulation must be implemented nationwide by January 1, 2014, which triggered a research boom on the internal control construction of domestic administrative institutions. With the continuous increase of this research boom and China's investment in education, the Ministry of Education of China (MEC) has continually emphasized and promoted the construction of internal control of universities directly under MEC in recent years. During this period, the internal control audit has become a recontrol of the internal control of universities and a research hotpot of all social circles. In practice, at the end of 2016, MEC required that universities directly under MEC must fill out and report internal audit work, including the development of internal control audit. This was the first time that the statistics on the internal audit circumstances of universities directly under MEC listed the "internal control audit" as an independent audit item, which is enough to reflect the importance of MEC.

This article mainly investigates some universities directly under MEC and adopts a questionnaire survey and the experts' qualitative evaluation to research the defects of the current internal audit of universities in China and the influencing factors that affect the quality of the internal control audit of universities. The paper attempts to conduct profound analysis using the principal component analysis in order to find the most serious defects and the most critical factors. At last, the article puts forward more targeted and 
reasonable recommendations for the optimization of the internal control audit of universities, hoping that such optimization proposals will further promote the sound development of the internal control audit of universities.

\section{Literature Review}

Academic research on the internal control of enterprises has a long history, but research on the internal control of administrative institutions is more recent and on the rise. At present, the research on the internal control audit of universities has mainly occurred in three aspects, which are the defects of the internal control audit of universities, the causes of those defects, and suggestions for the optimization of the internal control audit of universities.

The defects of internal control audit in universities mainly include seven aspects. First, the audit coverage of internal control audit is not comprehensive enough, and the content is relatively narrow [1-4]. Second, the use of internal control audit results is not ideal $[2,5,6]$. Third, the internal control audit mainly focuses on postevaluation and lacks prior control and in-process supervision, and the audit process is not sound [2, 7-9]. Fourth, internal control audit lacks mature risk assessment mechanism and effective internal control environment $[7,10,11]$. Fifth, the system of internal control self-assessment in universities is not perfect and lacks a complete index system $[4,5,7,12-16]$. Sixth, the internal control audit implementation procedure is not standardized, and the focus is comparatively limited $[4,17]$. Seventh, internal control audit is too arbitrary and tend to be more formal $[12,16]$.

The causes of defects in internal control audit in universities mainly include seven aspects. First, the concept of internal audit in universities is weak $[4,7,13,15,18,19]$. Second, the process and system of internal control audit in universities are not perfect $[4,5,18-20]$. Third, internal auditors in universities have poor professional qualifications and skills, which cannot adapt to the current new environment $[16,18-20]$. Fourth, independence of internal audit institutions is insufficient in China universities [18, 19]. Fifth, there is a big obstacle to the implementation of risk management audit in universities [13, 15]. Sixth, risk of internal control audit in universities is high $[5,12,14]$. Seventh, the internal audit of universities does not focus on cost-effectiveness, resulting in the fact that funds cannot meet audit needs [18].

There are six main suggestions for the optimization of internal control audit in universities. First, a good internal control environment and risk assessment mechanism should be established [10, 12, 18]. Second, universities should change the concept of thinking and implement an internal control audit based on the overall framework of internal control in universities $[2,7,13]$. Third, both the construction of the audit team and the quality of personnel should be strengthened $[2,14,16,18,21]$. Fourth, responsibility of the leadership and self-assessment should be intensified $[5,22]$. Fifth, universities ought to raise the awareness of internal control of personnel and improve the internal control audit system and evaluation index system $[2,7,14,16,17]$. Sixth, universities are supposed to strengthen the supervision function of audit and improve the independence of internal audit institutions in universities $[18,19,21]$.

The above research results have established a good foundation for later studies. At the same time, this paper finds that the current research on "internal control audit in universities" is generally less theoretical than empirical. The empirical research mainly adopts analytic hierarchy process and fuzzy evaluation. Due to the lack of empirical support in some documents, the description of "deficiencies and causes of internal control audit in colleges and universities" is basically subjective, and objectivity and universality are doubtful. In the empirical research, the factors affecting the quality of internal control audit in universities have not been clearly distinguished, which may lead to the corresponding optimization suggestions, which may reduce the optimization effect. Therefore, the goal of this paper is to promote empirical research, combined with the investigation and principal component analysis, and fuse the qualitative evaluation information presented by the probabilistic hesitant fuzzy set [23-25] of the internal control audit of some universities directly under MEC, to find the most serious flaws in the current internal control audit of universities in China and the most critical factor affecting the quality of universities' internal control audit influencing factors, to further improve the objectivity, universality, and rationality of the internal control audit optimization recommendations for universities.

\section{The Questionnaire Survey and Analysis}

\subsection{Sample Selection and Data Sources}

3.1.1. Sample Selection. This article takes the auditing office of the universities directly under MEC as the survey object. Considering the representativeness of the sample and the availability of data, the selected universities cover the eastern, southern, western, northern, and central regions of China. The main representatives of universities in the eastern region include Donghua University, Nanjing University, Southeast University, China Pharmaceutical University, Hohai University, Nanjing Agricultural University, China University of Mining and Technology, and Jiangnan University. The main representatives of universities in the southern region include South China University of Technology, Chongqing University, Sichuan University, and Southwest University; the main representative of universities in the western region is Xinjiang University (double-firstclass university); the main representatives of universities in the northern region are Peking University, Tsinghua University, University of Science and Technology Beijing, and Jilin University; the main representatives of universities in Central Region are Central South University and Wuhan University.

3.1.2. Data Sources. Data collection methods are as follows: universities in Jiangsu Province mainly focus on on-site interviews; universities outside Jiangsu Province filled out questionnaires (star questionnaire online version) through 
online platforms such as the WeChat group (college audit sister group) and the QQ group (college internal audit group and educational audit work exchange group). Note that some alternatives and attributes are judged and then presented by the real numbers and the probabilistic hesitant elements, namely, PHFEs $[6,25]$, in the questionnaire results.

3.2. Content of the Investigation. The questionnaire survey was divided into three parts. The first part explores the basic situation of the internal control audit of universities, including ten aspects: which school the respondent works in; the position of the investigated person in the audit department (director, deputy chief, chief/deputy chief/member of the financial audit section, and chief/deputy chief/ member of the engineering audit section); whether the university under investigation has carried out internal control audit and the starting time and frequency; the object of the internal control audit of the university where the subject is located; the object of the internal control audit of the college where the subject is located (the whole school, two or more colleges/departments/units of the school, and individual colleges/departments/units of the school); subject of the internal control audit of the university in which the respondents serve (school as a whole, two or more colleges/ departments/units of the school, and individual colleges/ departments/units of the school); the scope of the internal control audit of the university where the subject is located (the overall internal control of the school, the comprehensive internal control of two or more aspects of the school, and the internal control of a single aspect of the school); the content and focus of the internal control audit of the universities where the respondents are located (internal control at the school unit level: control environment, risk assessment, control activities, information and communication, and internal supervision; internal control at school business level: internal control of budget operations, revenue and expenditure internal control of business, internal control of government procurement, internal control of asset management, internal control of construction project management, and internal control of contract management); types of audit projects for internal control audits carried out by the universities under investigation (independently carry out internal control audits, integrate budget execution and final accounts audit projects, integrate economic responsibility audit projects, integrate scientific research funding audit projects, integrate financial revenue and expenditure audit projects, and integrate other audit projects).

The second part of the investigation conducted by the university where the respondent is located is to investigate the defects of the internal control audit of the university, mainly including whether the internal control audit method and process are complete, whether the internal audit institution is independent, whether the internal auditor's business knowledge can adapt to the internal control audit, what is the effectiveness of the hired firm's internal control audit management, and whether the internal control audit finds problems and corrects them in a timely manner.
The third part is to investigate the influencing factors of the internal control audit quality of colleges and universities, including the leadership's support for internal control audit, the degree of cooperation of various departments in internal control audit, the lack or imperfection of internal control audit system and process, the degree of restriction on internal control auditing, whether the knowledge and skills of internal auditors meet the needs of internal control auditing, whether the funds for internal control auditing are sufficient, and the use of internal control audit results.

3.3. Survey Results and Analysis. The survey took back 110 questionnaires, eliminated 27 invalid questionnaires, and obtained 83 valid questionnaires. The effective response rate was $75.45 \%$.

\subsubsection{Descriptive Statistics of Survey Results}

(1) Investigation Results on the Basic Situation of Internal Control Audit in Universities. In this survey, the universities that received the most valid questionnaires were mainly in the eastern region, accounting for $67.74 \%$; the most positive responses were financial auditors, accounting for $63.3 \%$ of the questionnaires returned.

During the investigation, we found that although the 2009 "Internal Auditing Practice Guide No. 4-University Internal Auditing" (referred to as the "Guide," the same below) pointed out that the auditors can choose to audit all or part of the unit's internal control, some universities' auditors only accept the overall internal control audit of the school, denying that the audit of the internal control of parts of the school or individual colleges/departments/units is an internal control audit; individual colleges and universities have not independently carried out internal control audit projects but incorporate it into other audit projects. The survey results show that the publication of the "Guide" has only caused the initial concern of the Auditing Offices of various universities, and the implementation has not been popularized. The projects of university's internal control auditing projects have generally commenced throughout the country starting in 2016. That is, MEC clearly requires all universities to report internally. The frequency is usually once a year.

In addition, $60.98 \%$ of colleges and universities selected the audit department as the subject of internal control audit; $40.96 \%$ selected internal control auditing objects as schools as a whole; $39.76 \%$ selected internal control auditing objects as colleges, universities, departments, or units; and nearly $75 \%$ of universities chose the overall internal control of the school and two or more situations of comprehensive internal control of schools as the scope of internal control audit; only $30.12 \%$ of universities selected content and focus of internal control audit as all aspects of the school unit level and business level. $25.3 \%$ of universities selected the type of conducting independent internal control audits. Most universities integrate internal control auditing in other audit projects. 
(2) Investigation Results on the Defects of Internal Control Audit in Universities. According to the statistics of the survey, nearly $40 \%$ of the universities have not established internal control audit system and process; $96.34 \%$ of universities have independent internal audit structure; and $14.63 \%$ of the universities believe that the internal audit personnel's knowledge and skills can well adapt to the internal control audit; $28 \%$ of the universities believe that the management effect of internal control audit conducted by external firms is normal, not very good, or very bad; only $15.85 \%$ of the universities can rectify the problem of internal control audits timely.

(3) Survey Results of Factors Affecting the Quality of Internal Control Audits in Universities. The survey results show that the leadership of the university lacks sufficient understanding and support for conducting internal control audits, and the degree of cooperation among various departments of the school is not satisfactory. The proportion of "very good" selection is only $1.83 \% ; 3.67 \%$ of universities considered that the shortage of internal control audit system and process would hamper the implementation of internal control audits. It is no wonder that universities as a whole have insufficient emphasis on the establishment and perfection of internal control auditing systems; only $11.93 \%$ of colleges and universities believe that internal auditors fully possess the knowledge and skills of internal control auditing; $72.48 \%$ of colleges and universities think that the necessary funds for internal control audit are adequate or sufficient; $55 \%$ of colleges and universities thought that the situation of using internal control results is normal, not very good, or very bad.

3.4. Survey Results' Analysis Based on Principal Component Analysis. The survey used SPSS19.0 software to process the surveyed information. According to the severity of internal control auditing defects and the degree of influence of various factors restricting the quality of internal control auditing, the paper evaluates the value from low to high, that is, from the A to D or E option of the questionnaire to the value of 1 to 4 or 5 in turn. Moreover, the surveyed information presented by the PHFEs is transformed based on their score functions. Thus, we can fully show the uncertainty of the qualitative evaluation information given by the experts and directly calculate and model the qualitative information simultaneously.

3.4.1. Principal Component Analysis of Internal Control Audit Defects. There are five indicators of internal control audit defects, and this paper uses $Y 1-Y 5$ to indicate as shown in Table 1.

Firstly, the paper used the principal component analysis method; then it extracted three principal components from the five defects of the internal control audit. The cumulative variance contribution rate of the three principal components reaches $94.207 \%$ as shown in Table 2 , which can well explain the information contained in the original five indicators. Note that there are two indicators, namely, $Y 1$ and $Y 3$, which are evaluated by the PHFE information and then transformed into real numbers based on their score functions.

Secondly, the paper extracted the eigenvectors corresponding to the three principal components; that is, the coefficients of the three principal components corresponding to the original five indicators are shown in Table 3.

Thirdly, the paper took the proportion of the eigenvalues as the weight; the above three principal components can be weighted and averaged in order to obtain a comprehensive principal component index $F_{B}$, which can represent the synthesis of the listed defects. The expression is as follows:

$$
F_{B}=0.639628 \times F_{B 1}+0.221545 \times F_{B 2}+0.138827 \times F_{B 3} .
$$

Furthermore, the expressions of $F_{B 1}, F_{B 2}$, and $F_{B 3}$ are brought into the above formula, and the expression of $F_{B}$ on the five indexes is

$$
\begin{aligned}
F_{B}= & 0.488705 \times Y_{1}-0.02888 \times Y_{2}+0.299625 \times Y_{3} \\
& +0.280475 \times Y_{4}+0.270253 \times Y_{5} .
\end{aligned}
$$

By comparing the weights of the above five indicators, we can see the importance of the five indicators. According to the weights of the five indicators, the comparison results obtained are as follows.

According to Table 4, it can be seen that the most serious defects in the internal control audit of universities at this stage are as follows: the defects represented by $Y_{1}, Y_{3}$, and $Y_{4}$, that is, the internal control audit system and process, are not perfect, and the knowledge and skills of internal auditors in colleges and universities cannot adapt to internal control audits, and the management effects of internal control audit conducted by external firms are not good.

\subsubsection{Principal Component Analysis of Influencing Factors on} Internal Control Audit Quality. There are six main influencing factors that affect the quality of internal control audit in universities. This paper uses $Z 1-Z 6$ to indicate, and the corresponding explanations are given in Table 5 . Note that there are three main influencing factors, namely, $Z 2, Z 3$, and $Z 4$, which are evaluated by the PHFE information and then transformed into the real numbers based on their score functions.

Firstly, the paper used the principal component analysis method; then, it extracted three principal components from six influencing factors. The cumulative variance contribution rate of the three principal components is $87.8 \%$ as shown in Table 6 , which can well explain the information contained in the original six indicators.

Secondly, the paper extracted the Characteristic Vectors corresponding to the three principal components; that is, the coefficients of the three principal components corresponding to the original six indicators are shown in Table 7.

Thirdly, the paper took the proportion of the eigenvalues as the weight; the above three principal components can be weighted and averaged in order to obtain a comprehensive principal component index $F_{C}$, which can represent the synthesis of the listed defects. The expression is as follows: 
TABLE 1: Meaning of indicators of internal control audit defects.

\begin{tabular}{lcc}
\hline Index & Meaning & $\begin{array}{c}\text { Defect severity values (from low to } \\
\text { high) }\end{array}$ \\
\hline$Y_{1}$ & The degree of imperfection in internal control audit methods and procedures & $1-5$ \\
$Y_{2}$ & Internal audit agency does not have independence & $1-5$ \\
$Y_{3}$ & Internal auditor's business knowledge cannot adapt to the internal control audit's defect & $1-5$ \\
$Y_{4}$ & External offices defective in the effectiveness of internal control audit management & $1-5$ \\
$Y_{5}$ & The problem that internal control audit found was not resolved in a timely manner & $1-5$ \\
\hline
\end{tabular}

TABLE 2: Eigenvalues and cumulative contribution rates for internal control auditing defects.

\begin{tabular}{lccc}
\hline No. & Eigenvalues & Variance contribution rate (\%) & Cumulative variance contribution rate (\%) \\
\hline 1 & 1.995 & 60.253 & 60.253 \\
2 & 0.691 & 20.868 & 81.121 \\
3 & 0.433 & 13.086 & 94.207 \\
4 & 0.165 & 4.984 & 99.191 \\
5 & 0.027 & 0.809 & 100.000 \\
\hline
\end{tabular}

TABLE 3: Characteristic vectors of internal control audit defects.

\begin{tabular}{lccc}
\hline Index & The first principal component $F_{B 1}$ & The second principal component $F_{B 2}$ & The third principal component $F_{B 3}$ \\
\hline$Y_{1}$ & 0.9211 & -0.3525 & -0.1611 \\
$Y_{2}$ & -0.0290 & -0.0457 & 0.0106 \\
$Y_{3}$ & 0.2457 & 0.3838 & 0.3997 \\
$Y_{4}$ & 0.2365 & 0.8349 & -0.4149 \\
$Y_{5}$ & 0.1862 & 0.1708 & 0.8024 \\
\hline
\end{tabular}

TABLE 4: Ranking results of internal control audit defect indicators.

\begin{tabular}{lcccc}
\hline$Y_{1}$ & $Y_{3}$ & $Y_{4}$ & $Y_{5}$ & $Y_{2}$ \\
\hline 0.488705 & 0.299625 & 0.280475 & 0.270253 & -0.02888 \\
\hline
\end{tabular}

TABLE 5: Meaning of indicators of internal control auditing factors.

\begin{tabular}{lcr}
\hline Index & Meaning & Influence level (from low to high) \\
\hline$Z_{1}$ & Leadership does not support internal control audit & $1-5$ \\
$Z_{2}$ & Noncooperation degree of internal control audit among various departments & $1-5$ \\
$Z_{3}$ & Restriction degree due to the imperfections of the internal control audit system and process & $1-5$ \\
$Z_{4}$ & Incompleteness of knowledge and skills of internal auditors & $1-5$ \\
$Z_{5}$ & Insufficient funding for internal control audit & $1-5$ \\
$Z_{6}$ & Poor use of audit results & $1-5$ \\
\hline
\end{tabular}

TABLE 6: Eigenvalues, cumulative variance, and contribution rate of internal control audit influencing factors.

\begin{tabular}{lccc}
\hline No. & Eigenvalues & Variance contribution rate (\%) & Cumulative variance contribution rate (\%) \\
\hline 1 & 2.199 & 56.900 & 56.900 \\
2 & 0.824 & 21.322 & 78.222 \\
3 & 0.370 & 9.578 & 87.800 \\
4 & 0.224 & 5.794 & 93.594 \\
5 & 0.153 & 3.959 & 97.553 \\
6 & 0.095 & 2.447 & 100.000 \\
\hline
\end{tabular}


TABLE 7: Characteristic vectors of internal control audit influencing factors.

\begin{tabular}{lccc}
\hline Index & The first principal component $F_{C 1}$ & The second principal component $F_{C 2}$ & The third principal component $F_{C 3}$ \\
\hline$Z_{1}$ & 0.4120 & 0.2269 & 0.2893 \\
$Z_{2}$ & 0.2691 & 0.1774 & 0.5984 \\
$Z_{3}$ & 0.3756 & -0.9210 & 0.0822 \\
$Z_{4}$ & 0.4046 & 0.1575 & -0.0838 \\
$Z_{5}$ & 0.3203 & 0.0936 & -0.7349 \\
$Z_{6}$ & 0.5921 & 0.1873 & -0.0707 \\
\hline
\end{tabular}

$F_{C}=0.648099 \times F_{C 1}+0.242853 \times F_{C 2}+0.109048 \times F_{C 3}$.

Furthermore, the expressions of $F_{C 1}, F_{C 2}$, and $F_{C 3}$ are brought into the above formula, and the expression of $F_{C}$ on the six indexes is

$$
\begin{aligned}
F_{C}= & 0.353668 \times Z_{1}+0.282740 \times Z_{2}+0.028722 \times Z_{3} \\
& +0.291332 \times Z_{4}+0.150178 \times Z_{5}+0.421516 \times Z_{6} .
\end{aligned}
$$

By comparing the weights of the above six indicators, we can see the importance of the six indicators. According to the weights of the six indicators, the comparison results are as follows.

According to Table 8, it can be seen that the most critical influencing factors in the quality of internal control audits in universities at this stage are $Z_{6}$ (the results of internal audit of colleges and universities are difficult to use rationally), $Z_{1}$ (the leadership's support for internal control audits is poor), and $Z_{4}$ (insufficient business knowledge and skills of internal auditors in conducting internal control audits).

3.4.3. Robustness Test. Based on regression analysis, the paper verified the credibility of the relationship between internal control audit defects in universities and the factors affecting quality of internal control audit. Then, a multiple regression analysis model was established. Independent variables were $Z_{6}, Z_{1}$, and $Z_{4}$; the dependent variable was $F_{B}$. The influence of these three factors on the comprehensive evaluation index $F_{B}$ of internal control auditing defects was examined. The parameter estimation results of the regression model are shown in Table 9.

The multiple regression model expression is

$$
F_{B}=0.400 \times Z_{1}+0.424 \times Z_{4}+0.483 \times Z_{6} .
$$

Among them, the regression coefficient of the regression model is $R^{2}=0.972$, the whole equation passes the significance test, and the $P$ value of each influencing factor is less than 0.1 or even less than 0.05 , which indicate that the confidence degree of the regression result is high. Therefore, the regression result clearly shows that $Z_{6}$ (the results of the auditing of internal control of universities are difficult to use rationally), $Z_{1}$ (the leadership's support for internal control auditing is poor), and $Z_{4}$ (the business knowledge and skills of internal auditors conducting internal control auditing are insufficient) are indeed the most critical influencing factors for the comprehensive principal component $F_{B}$ of internal control audit defects.
TABLE 8: Ranking results of internal control auditing influencing factors.

\begin{tabular}{lccccc}
\hline$Z_{6}$ & $Z_{1}$ & $Z_{4}$ & $Z_{2}$ & $Z_{5}$ & $Z_{3}$ \\
\hline 0.421516 & 0.353668 & 0.291332 & 0.28274 & 0.150178 & 0.028722 \\
\hline
\end{tabular}

TABLE 9: Multiple regression results' table.

\begin{tabular}{lcccc}
\hline Index & Coefficient & Standard error & $T$-test statistic & $P$ value \\
\hline$Z_{1}$ & 0.400 & 0.234 & 1.714 & 0.091 \\
$Z_{4}$ & 0.424 & 0.193 & 2.194 & 0.031 \\
$Z_{6}$ & 0.483 & 0.158 & 3.054 & 0.003 \\
\hline
\end{tabular}

\section{Conclusions and Suggestions}

The defects of internal control audit in universities are closely related to the quality of internal control audit. To some extent, the fewer the defects of internal control audit, the higher the quality of internal control audit, and vice versa. Based on the above investigation and analysis results with respect to the qualitative evaluation given by experts and presented by the real numbers and PHFEs, this paper is based on the critical degree of the internal control audit defect severity and the influencing factors of internal control audit quality. It is suggested that, according to the principle of importance, the internal audit of universities must be gradually optimized as follows.

4.1. Establish and Improve the Internal Control Audit System and Process. A perfect audit system and a standardized audit process are the institutional guarantees for the successful implementation of the audit project. Establishing and improving the internal control audit system and process are the primary way to optimize internal audit in universities. Universities should continue to advance the integration of systems, processes, and informatization based on the school's internal control objectives, information-based service processes, process-oriented service systems, and institutionalized service management and constantly improve internal control audit systems and processes.

4.2. Promote the Application of the Results of Internal Control Audit Continuously. Internal control audit and result application are the relationship between process and end point. In order to reflect the value of internal control audit, it is necessary to strengthen the application of the results of internal control audit. Universities should promote the 
follow-up review system of disclosure of internal control audit results and feedback on the implementation of reforms. The evaluation of the use of internal control audit results should be used as the annual assessment indicator of the relevant person in charge of the relevant departments of the school. This index linked to personal interests is directly related to its removal, promotion, punishment, reward, etc.

4.3. Raise the Attention of the Leadership. The construction of internal control is a leading project, as is the internal control audit. Only when university presidents have paid enough attention can the development of internal control audits truly go smoothly. Colleges and universities need to increase publicity, emphasize the importance of internal control audit, and make them deeply rooted in people's minds, so as to mobilize the enthusiasm of management, teachers, and students to cooperate; universities should increase information transparency and strengthen information among leaders, management, and students, so as to improve the effectiveness of communication and grasp the core business of internal control timely and systematically. The concerted efforts of all levels of the university can help to purify the internal control audit environment and improve the efficiency and quality of the internal control audit.

4.4. Strengthen the Construction of the Internal Audit Team. The second most serious flaw in the defect of internal control audit in universities and the third most important factor in the factors affecting the internal audit quality of universities are "the adaptability of the knowledge and skills of internal auditors is not powerful. The degree of weakness is that the internal auditors have insufficient business knowledge and skills to carry out internal control audits." In fact, the thirdranked defect, "the poor management effect of internal control audit conducted by external offices," is a deficient derivative of internal auditing power. Therefore, it is crucial to strengthen the construction of an internal audit team. It is necessary to establish a long-term auditing personnel training mechanism and motivate internal auditors to learn constantly. While improving their own auditing knowledge and skills, they must also pay attention to improving the management capabilities and level of external auditors of internal auditors.

4.5. Future Works. In this paper, we use the real numbers and PHFEs to show the experts and DMs' qualitative evaluation information in the given questionnaires. Then, the principal component analysis is applied to deal with these data and derive the above conclusions. It is pointed out that the PHFEs are used to fully show the subjective information and then transformed into the score values. After that, the principal component analysis can be effectively used. As the experts and DMs concluded, the PHFE is a convenient tool to describe their subjective evaluation. Then, how to further reasonably and effectively model the given PHFE information could be an interesting research direction in future. Moreover, we can find that the PHFE information is transformed firstly and then the principal component analysis is used to calculate them. In our opinion, this process is imperfect and then the whole model should be studied to analyze the principal components and calculate the PHFEs. Therefore, these directions are two important study issues to improve our methods which could be used to judge the subject defects and object defects of the current internal audit of universities in China, as well as the influencing factors that affect the quality of the internal control audit of universities. This will be our next works.

\section{Data Availability}

The data used to support the findings of this study are available from the corresponding author upon request.

\section{Conflicts of Interest}

The authors declare that there are no conflicts of interest regarding the publication of this paper.

\section{Acknowledgments}

This work was supported by the National Key Research and Development Program of China (no. 2018AAA0100202).

\section{References}

[1] B. C. Fitzgerald, T. C. Omer, and M. Anne, "Audit partner tenure and internal control reporting quality: US evidence from the not-for-profit sector," Contemporary Accounting Research, vol. 35, pp. 334-364, 2018.

[2] L. Pan, "Application and development of internal control audit in universities," China Building Materials Science \& Technology, vol. 24, no. 5, pp. 162-164, 2015.

[3] R. Espahbodi and E. Hassan, "The impact on stock prices of deferral and elimination of internal control audit requirement for small firms," Journal of Contemporary Accounting \& Economics, vol. 15, pp. 158-166, 2019.

[4] Z. Yang and S. Zhang, "Research on the internal control audit in universities based on the governance perspective," Internal Control Audit in China, vol. 208, no. 10, pp. 22-27, 2016.

[5] L. Chen, X. Shi, and W. Xia, "SWOT analysis of internal control audit in universities and its optimization path," Friends of Accounting, vol. 23, pp. 110-113, 2016.

[6] W. Zhou and Z. Xu, "Group consistency and group decision making under uncertain probabilistic hesitant fuzzy preference environment," Information Sciences, vol. 414, pp. 276288, 2017.

[7] D. Ma, "Research on internal control audit in universities," Business Accounting, vol. 8, pp. 62-64, 2015.

[8] M. Sterin, "The influence of audit committee expertise on firms' internal controls: evidence from mergers and acquisitions," Accounting Horizons, vol. 34, pp. 193-211, 2020.

[9] N. Chun, "The impact of noncompliance and internal control deficiencies on going concern audit opinions and viability of nonprofit charitable organizations," Journal of Accounting Auditing and Finance, vol. 35, pp. 637-663, 2020.

[10] Y. He, "Discussion on the internal control audit in universities based on the governance perspective," Western China Quality Education, vol. 3, no. 10, p. 30, 2017. 
[11] C. Ma, "Research on internal control audit in universities," Enterprise Reform and Management, vol. 23, pp. 151-152, 2015.

[12] C. Yu and W. Xia, "Analysis on the status quo of internal control auditing in universities in the new era and countermeasures," China-Today Forum, vol. 12, pp. 95-96, 2013.

[13] H. Tang, "Analysis on the difficulties and breakthrough paths of internal control audit in universities," Journal of Fujian Agriculture and Forestry University, vol. 15, no. 4, pp. 58-61, 2012.

[14] J. Shi, L. Tang, and T. Zhang, "Research on the existing problems and improvement countermeasures in the process of internal control audit in universities," Science \& Technology Economic Guide, vol. 32, p. 178, 2017.

[15] Q. Ren, Y. Tian, and J. Wu, "Problems and countermeasures of internal control audit in universities," China Township Enterprises Accounting, vol. 11, pp. 153-154, 2013.

[16] Z. Zhou, "Talking about the problems and countermeasures of school internal control audit," Administrative Business Assets and Finance, vol. 24, pp. 77-78, 2015.

[17] N. Liu, "Investigation and analysis of internal control audit in universities and countermeasures for improvement," Modern Auditing \& Economy, vol. 1, pp. 42-43, 2017.

[18] A. Zhang, "Research on internal control audit in universities," Northern Economy and Trade, vol. 5, pp. 67-68, 2017.

[19] R. Wang, "The influencing factors and countermeasures of internal control audit quality in universities," Journal of Fujian Medical University (Social Science Edition), vol. 17, no. 3, pp. 21-23, 2016.

[20] W. Zhang, "On how to strengthen the internal control audit in universities in the new situation," China Economist, vol. 3, pp. 127-128, 2017.

[21] Z. Xi, "Analysis on the influencing factors of the quality of internal control audit in universities and coping strategies," Economic Research Guide, vol. 2, pp. 165-166, 2017.

[22] J. Lu, "Several reflections on the internal control audit in universities under the new situation," Jiangsu Science \& Technology Information, vol. 24, pp. 35-37, 2014.

[23] S. Zhang, Z. Xu, and Y. He, "Operations and integrations of probabilistic hesitant fuzzy information in decision making," Information Fusion, vol. 38, pp. 1-11, 2017.

[24] W. Zhou and $\mathrm{Z}$. Xu, "Probability calculation and element optimization of probabilistic hesitant fuzzy preference relations based on expected consistency," IEEE Transactions on Fuzzy Systems, vol. 26, no. 3, pp. 1367-1378, 2018.

[25] Z. Xu and W. Zhou, "Consensus building with a group of decision makers under the hesitant probabilistic fuzzy environment," Fuzzy Optimization and Decision Making, vol. 16, no. 4, pp. 481-503, 2017. 